\title{
Oxidative Stress in Diabetic Neuropathy: Strategies for Treatment
}

\section{Stephanie Eid ${ }^{2}$, Charbel Massaad ${ }^{1^{*}}$ and Assaad A. Eid ${ }^{3^{*}}$}

${ }^{1}$ UMR-S 1124 INSERM, Paris Descartes University, Sorbonne Paris Cité University, Centre Interdisciplinaire Chimie Biologie Paris (FR 3567, CNRS) 75270, Paris Cedex 6, France

2UMR-S 1124 INSERM, Paris Descartes University, Sorbonne Paris Cité University, Centre Interdisciplinaire Chimie Biologie-Paris Cedex 6, France

${ }^{3}$ Department of Anatomy, Cell Biology and Physiological Sciences, Faculty of Medicine, American University of Beirut, Beirut, Lebanon

\section{Diabetes}

Diabetes is a major public health problem. In 2014, the global prevalence of diabetes was estimated to be $9 \%$ among adults aged 18 years old and above [1]. The incidence of diabetes has increased immensely in the past 10 years. The World Health Organization (WHO) projects that diabetes will be the seventh leading cause of death in 2030 [2]. This alone makes it an epidemic disease. Diabetes is associated with a number of metabolic risk factors that contribute to a high rate of micro and macrovascular events. One of the most common and debilitating complications associated with diabetes is Diabetic Neuropathy (DN); it affects about $10 \%$ of patients newly diagnosed with diabetes and more than $50 \%$ of patients with longstanding diabetes [3].

\section{Diabetic neuropathy}

Diabetic neuropathy can be classified as peripheral, autonomic, proximal, or focal. Each affects different parts of the body in various ways [4]. Diabetic Peripheral neuropathy (DPN), the most common type of diabetic neuropathy is associated with impaired nerve conduction, abnormal thermal perception, axonal atrophy, demyelination, blunted regenerative potential, and loss of nerve fibers [5]. Additionally, DN can lead to autonomic dysfunction, which manifests as orthostatic hypotension, fainting, arrhythmias, gastrointestinal dysmotility, bloating, diarrhea, etc [6]. Patients diagnosed with DN experience an increased sensitivity to pain (hyperalgesia), as well as an increased responsiveness to non-painful stimuli (allodynia) [7-11]. With the progression of the disease, pain is replaced with complete numbness followed by serious foot problems, ultimately resulting in ulcerations and leading to foot amputation [12-14]. Although DPN has long been viewed as neurocentric, it is now widely accepted that the rate of peripheral nervous system deterioration is intimately correlated with the significant pathological interactions between neurons, Schwann cells, and microvascular endothelium [15-17]. In the last decade, much attention has been focused on the role of hyperglycemia in the progression of DPN. Clinical studies have established that intensive glycemic control and improved blood glucose levels reduce the incidence and slow the progression of DPN, thus clearly implicating hyperglycemia in the initiation of distal neuropathy [18-21]. However, the underlying mechanisms leading to diabetic peripheral neuropathy are not well described and need further investigations.

\section{Diabetic neuropathy and oxidative stress}

In recent studies, we and others have shown that high glucose/ hyperglycemia is associated with increased systemic and cellular oxidative stress, now considered as a common pathway of cellular injury leading to diabetic complications [22-27]. It has been suggested that antioxidant treatment prevents or slows the development of neuropathy in animal models of diabetes, signifying a major pathogenic role of reactive oxygen species (ROS) in the pathology of DN [28-30]. However the sources of ROS as well as the mechanistic pathways that are altered by the production of these radicals are still unknown (Figure 1).

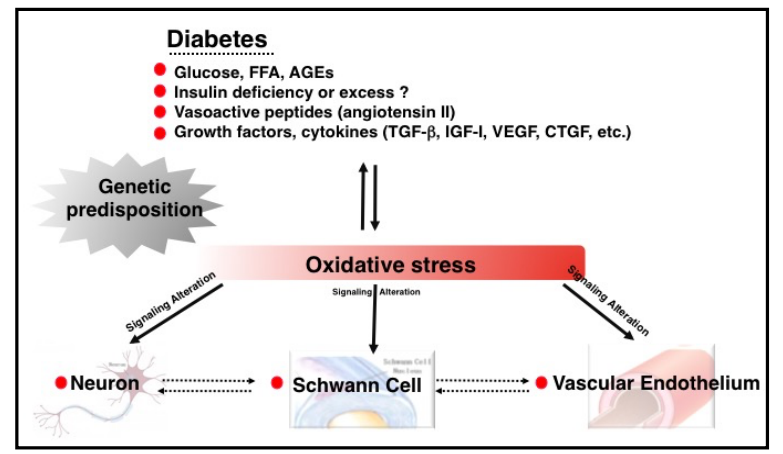

Figure 1: ROS induced peripheral nervous system injury in diabetes: suggested mechanism.

\section{Conclusion}

Understanding the cellular and molecular signaling mechanisms altered by ROS production in the onset and development of DPN is fundamental in developing new intervention strategies that would benefit diabetic patients and stop the progression or block the onset of DPN.

\section{Acknowledgment}

$A A E$ and $C M$ were funded by a "CEDRE" research grant.

\section{References}

1. Geneva, WHO (2014) Global status report on non communicable diseases.

2. Mathers CD, Loncar D (2006) Projections of global mortality and burden of disease from 2002 to 2030 . PLoS Med 3: e442.

3. Shakeel M. Recent advances in understanding the role of oxidative stress in diabetic neuropathy. Diabetes \& Metabolic Syndrome: Clinical Research \& Reviews.

4. Callaghan BC, Cheng HT, Stables CL, Smith AL, Feldman EL (2012) Diabetic neuropathy: clinical manifestations and current treatments. The Lancet Neurology 11: 521-534:

*Corresponding author: Charbel Massaad, Professor, UMR-S 1124 INSERM, Paris Descartes University, Sorbonne Paris Cité University, Centre Interdisciplinaire Chimie Biologie Paris (FR 3567, CNRS) 75270, Paris Cedex 6, France, Tel: +33-142862222; E-mail: charbel.massaad@parisdescartes.fr

Assaad A. EidAssociate ProfessorDepartment of Anatomy, Cell Biology and Physiological Sciences, Faculty of Medicine, American University of Beirut, P.O.Box: 11-0236, Riad el- Solh 1107 2020, Beirut, Lebanon.Tel: +961-1-350000 Ext 4781Email: HYPERLINK “mailto:ae49@aub.edu.Ib” ae49@aub.edu.lb

Received: October 02, 2015; Accepted: January 04, 2016; Published: January 07, 2016

Citation: Massaad C, Eid S, Eid AA (2016) Oxidative Stress in Diabetic Neuropathy: Strategies for Treatment. Diabetes Case Rep 1:101. doi: 10.4172/2572-5629.1000101

Copyright: (c 2016 Massaad C, et al. This is an open-access article distributed under the terms of the Creative Commons Attribution License, which permits unrestricted use, distribution, and reproduction in any medium, provided the original author and source are credited. 
Citation: Massaad C, Eid S, Eid AA (2016) Oxidative Stress in Diabetic Neuropathy: Strategies for Treatment. Diabetes Case Rep 1:101. doi: 10.4172/25725629.1000101

5. Boulton AJ, Malik RA, Arezzo JC, Sosenko JM (2004) Diabetic somatic neuropathies. Diabetes care 27: 1458-1486.

6. Vinik Al, Maser RE, Mitchell BD, Freeman R (2003) Diabetic autonomic neuropathy. Diabetes Care 26: 1553-79.

7. Dworkin RH, Jensen MP, Gammaitoni AR, Olaleye DO, Galer BS (2007) Symptom profiles differ in patients with neuropathic versus non-neuropathic pain. The Journal of Pain 8: 118-126.

8. Dworkin RH, O'connor AB, Backonja M, Farrar JT, Finnerup NB, et al (2007) Pharmacologic management of neuropathic pain: evidence-based recommendations. Pain 132: 237-251.

9. Dworkin RH, Turk DC, Farrar JT, Haythornthwaite JA, Jensen MP, et al. (2005) outcome measures for chronic pain clinical trials: IMMPACT recommendations. Pain 113: 9-19.

10. Jensen MP, Dworkin RH, Gammaitoni AR, Olaleye DO, Oleka N, et al. (2006) Do pain qualities and spatial characteristics make independent contributions to interference with physical and emotional functioning? The Journal of Pain 7: 644-653.

11. Jensen TS, Backonja MM, Jiménez SH, Tesfaye S, Valensi P, et al. (2006) New perspectives on the management of diabetic peripheral neuropathic pain. Diabetes and Vascular Disease Research 3: 108-119.

12. Feldman EL, Steven MJ, Greene DA. Diabetic neuropathy. In: Turtle K and Osato S (Eds.) Diabetes in the New Millenium, 1999 (pp. 387-402). Sydney: The Endocrinology and Diabetes Research Foundation of the University of Sydney.

13. Feldman EL, Stevens MJ, Russell JW, Peltier A, Inzucchi S, Porte JD, Sherwin RS,Baron A. Somatosensory neuropathy. In Inzucchi S (Ed). The Diabetes Mellitus Manual, 2005 (pp. 366-384). United States: McGraw-Hill.

14. Feldman EL, Stevens MJ, Russell JW, Greene DA. Somatosensory neuropathy. In: Porte JD, Sherwin RS and Baron A (Eds). Ellenberg and Rifkin's Diabetes Mellitus. 2002 (pp. 771-788). Philadelphia: McGraw Hill.

15. Dyck PJ, Giannini C (1996) Pathologic alterations in the diabetic neuropathies of humans: a review. Journal of Neuropathology \& Experimental Neurology 55: 1181-1193.

16. Vincent AM, Hinder LM, Pop-Busui R, Feldman EL (2009) Hyperlipidemia: a new therapeutic target for diabetic neuropathy. Journal of the Peripheral Nervous System 14: 257-267.

17. Vincent AM, Callaghan BC, Smith AL, Feldman EL (2011) Diabetic neuropathy: cellular mechanisms as therapeutic targets. Nature Reviews Neurology 7: 57383.

18. Obrosova IG (2009) Diabetic painful and insensate neuropathy: pathogenesis and potential treatments. Neurotherapeutics 6: 638-647.

19. Writing Team for the Diabetes Control and Complications Trial/Epidemiology of Diabetes Interventions and Complications Research Group (2002) Effect of intensive therapy on the microvascular complications of type 1 diabetes mellitus. JAMA 287: 2563-2569.

20. Stratton IM, Adler AI, Neil HA, Matthews DR, Manley SE, et al. (2000) Association of glycaemia with macrovascular and microvascular complications of type 2 diabetes (UKPDS 35): prospective observational study. British Medical Journal 327: 405-412.

21. Boulton AJM, Gries FA, Jervell JA (1998) Guidelines for the diagnosis and outpatient management of diabetic peripheral neuropathy. Diabetic Medicine 15: $508-514$

22. Eid S, Abdul-Massih C, El-Khuri CM, Hamdy A, Rashid A, et al. (2014) New Mechanistic Insights in the Development of Diabetic Nephropathy: Role of Cytochromes P450 and Their Metabolites. Journal of Endocrine Disorders 1 : 1006

23. Eid S, Maalouf R, Jaffa AA, Nassif J, Hamdy A, et al. (2013) 20-HETE and EETs in diabetic nephropathy: a novel mechanistic pathway. PloS one 8: e70029.

24. Eid S, Abou-Kheir W, Sabra R, Daoud G, Jaffa A, et al. (2013) Involvement of Renal Cytochromes P450 and Arachidonic Acid Metabolites in Diabetic Nephropathy. Journal of Biological Regulators and Homeostatic Agents 27: 693-703.

25. Eid AA, Ford BM, Bhandary B, de Cassia Cavaglieri R, Block K, et al. (2013) Mammalian target of rapamycin regulates Nox4-mediated podocyte depletion in diabetic renal injury. Diabetes 62: 2935-2947.

26. Vincent AM, Hayes JM, McLean LL, Vivekanandan-Giri A, Pennathur S, et al. (2009) Dyslipidemia-induced neuropathy in mice: the role of oxLDL/LOX-1. Diabetes 58: 2376-85.

27. El-Omar MM, Lord R, Draper NJ, Shah AM (2003) Role of nitric oxide in posthypoxic contractile dysfunction of diabetic cardiomyopathy. European Journal of Heart Failure 5: 229-39.

28. Cameron NE, Cotter MA, Archibald V, Dines KC, Maxfield EK (1994) Antioxidant and pro-oxidant effects on nerve conduction velocity, endoneurial blood flow and oxygen tension in non-diabetic and streptozotocin-diabetic rats. Diabetologia 37: 449-459.

29. Coppey LJ, Gellett JS, Davidson EP, Yorek MA (2003) Preventing superoxide formation in epineurial arterioles of the sciatic nerve from diabetic rats restores endothelium-dependent vasodilation. Free radical research 37: 33-40.

30. Sayyed SG, Kumar A, Sharma SS (2006) Effects of U83836E on nerve functions, hyperalgesia and oxidative stress in experimental diabetic neuropathy. Life sciences 79: 777-783. 